\title{
Role of Partial Androgen Deficiency of Aging Men in Development of the Metabolic Syndrome
}

\author{
Alexander V. Pechersky ${ }^{1}$ \\ ${ }^{1}$ Department of Urology, North-West State Medical University named after I.I. Mechnikov, St. Petersburg, \\ Russia \\ a_pechersky@mail.ru
}

\begin{abstract}
Insulin resistance, on an equal basis with an increase in proliferative activity, is a manifestation of metabolic syndrome. They reflect a set of compensatory and adaptive reactions that develop in men over 35-40 years old, and are substantially caused by a decrease in testosterone production. The inverse development of the specified compensatory reactions is observed following correction of partial androgen deficiency of aging men.
\end{abstract}

Keywords: testosterone, insulin resistance, metabolic syndrome

\section{INTRODUCTION}

Once people reach 35-40 years of age, they have a decrease in their pool of pluripotent stem cells [1], show a violation of tissue renewal, a decrease in the number of cell-producers of testosterone (Leidig cells), and a reduction in testosterone circulating in the blood $[2,3,4]$. This reduction of testosterone is named partial androgen deficiency of aging men (PADAM) [5].

Cells of a number of tissues have androgen receptors. These cells, in the process of their development from low-differentiated androgen-independent cells, transform into differentiated androgen-dependent cells [6]. Low-differentiated progenitor cells show incipient characters of differentiation, and continue division. When dividing, they produce progeny, a part of which continues to divide, while another part remains low-differentiated [7]. When cells acquire androgen receptors, their further division and differentiation becomes impossible without the availability of a sufficient amount of testosterone increted in the physiological impulse regime by Leidig cells $[8,9]$.

PADAM violates division and differentiation of androgen-dependent cells. Deficiency of testosterone production results in atrophy of tissues consisting of these cells $[2,10]$. The answer to insufficient production of testosterone is given by a series of compensatory-adaptive reactions affecting autocrine, paracrine and endocrine levels [8]. Compensatory reactions are aimed at additional formation of mitogenic factors (cell growth factors, $5 \alpha$-dihydrotestosterone, $17 \beta$-estradiol, insulin, somatotropic hormone and other factors), having a stimulating effect on proliferation of the epithelium and other tissues. A decrease in the level of testosterone induces an increase in mitotic activity, disruption of regulation of cells, as well as inhibition of apoptosis. The intensity of these reactions is proportional to the degree of reduction in testosterone production $[8,9,10,11]$. An increase in mitogenic stimulation in patients older than 35-40 years old, associated with a decrease in sex hormones, is complemented by an increase in mitogenic stimulation caused by violation of tissue regeneration $[2,3,4]$.

PADAM provokes a breach of the mechanisms of regulation in the system of the gonads-hypophysis-hypothalamus, including an increase in activity of the hypophysis [12]. In view of the interdependence of the neurohumoral regulatory processes [13], a reduction in the production of testosterone is reflected on endocrinal regulation as a whole $[8,9,11,14,15]$. 
Change in Adenohypophysis Regulation among Aging Men With Partial Androgen DEFICIENCY

As a result of the interaction of neurohumoral regulatory processes, the age-related decrease in testosterone production among aging men is reflected in the entire system of hypothalamic-pituitary regulation $[8,9,11,14,15]$. A decreased testosterone level stimulates both incretion of luteinizing hormone (LH), and the incretion of gonadotropin-releasing hormone as well [13], and, secondarily, of follicle-stimulating hormone (FSH).

In the presence of PADAM one can observe an increase in the activity of $5 \alpha$-reductase and aromatase, and, accordingly, an increase in the levels of 5a-dihydrotestosterone and $17 \mathrm{~b}$-estradiol as well $[8,11]$. The increased levels of 5a-dihydrotestosterone and 17b-estradiol suppress the incretion of LH, FSH and gonadotropin-releasing hormone by the principle of negative feedback. For this reason, some men with PADAM don't have an increase in LH $[8,13,14,15]$.

When the level of testosterone decreases, one can observe an increase in the level of prolactin [8]. An increase in the production of $17 \mathrm{~b}$-estradiol leads to a reduction in the content of prolactin-inhibiting factor - dopamine - in the hypothalamus. Thus, estrogens have a direct activating influence on the incretion of prolactin by the hypophysis [13].

An increase in the somatotropic hormone (STH) level is also connected to an increase in $17 \beta$-estradiol. This is proven by the results of functional trials with estrogens. In these trials, one can observe an intensification of the incretion of STH [13]. An increase in the level of STH causes an increase in the formation of insulin-like growth factor-1 (IGF-1). An increase in the level of IGF-1 accompanies insulin resistance and a growth of tolerance to glucose [13].

PADAM leads to the development of insulin resistance $[8,15,16]$. Hyperglycemia develops in response. Insulin resistance leads to growth in the level of insulin. This insulin, together with a decrease in sensitivity of hypothalamic centers to the slowdown of glucose, leads to the incretion of growth hormone-releasing factor and corticoliberin by neurons of the hypothalamus into the portal system of the hypophysis, as well as suppresses the incretion of somatostatin. Growth hormone-releasing factor stimulates the incretion of somatotropic hormone - the contrinsular hormone. An increase in the concentration of STH leads to an increase in the production of IGF-1 in the liver. Resistance to insulin is accompanied by resistance to IGF-1 as well, which is capable of connecting to insulin receptors. The formation of STH is additionally stimulated by vitamin D [13], the level of which also increases when the level of testosterone goes down [8]. Corticotropin-releasing hormone creates a surge of adrenocorticotropic hormone, which increases the incretion of another contrinsular hormone, cortisol, in the adrenal cortex [13].

\section{The Influence of Partial Androgen Deficiency among Aging Men on the Impulse MODE OF INCRETION OF SOME HORMONES}

Information from the central nervous system, which is transferred in the form of nerve impulses which follow one after another, is transformed into an impulse rhythm of formation of hormones $[9,17]$.

As testosterone production goes down as men get older, the agreement between the central and peripheral core of the hypothalamus-hypophysis-gonad system is broken down. Leidig cells are not able to ensure adequate production of testosterone in response to the incretion of $\mathrm{LH}$ among men after 35-40 years of age. Patients who have PADAM demonstrate that the impulse incretion of gonadotropin-releasing hormone and LH isn't accompanied by an adequate impulse incretion of testosterone. The central nervous system understands this state to be an even deeper manifestation of androgen deficit [9]. There is thus a compensatory increase in the levels of gonadotropin-releasing hormone, LH, and FSH using a mechanism of inverse feedback [13]. Despite 
the increase in the level of testosterone, the mode for testosterone incretion becomes non-physiological, and gradually becomes tonic. The reaction of Leidig cells in tonic mode to the impulse formation of gonadotropin-releasing hormone and LH among men with PADAM is accompanied by a gradual transition to a tonic regime of hormone incretion by the hypophysis and hypothalamus [9].

These changes lead to limitation and distortion of the information being transferred, which regulates a whole series of physiological processes, including cell proliferation. Suppression of the impulse incretion of gonadotropin-releasing hormone, in turn, is reflected in the correlation of LH and FSH, and in the formation of cell growth factors. In relation to this, the frequency of the rhythm of formation of gonadotropin-releasing hormone, which determines the correlation between LH and FSH, has a direct influence on the level of cell growth factors, and, accordingly, on cell proliferation $[9,13]$.

The long and continuous (in the tonic mode) influence of gonadotropin-releasing hormone leads to desynthesization of this hormone's receptors on gonadotropin cells, and to suppression of the incretion of LH and FSH, despite the remaining deficit of testosterone $[13,18]$. Thus, among some patients with PADAM, the original levels of LH and FSH don't exceed the normal referential interval $[9,17]$. The use of analogues of gonadotropin-releasing hormone, which have a suppressing influence on gonadotropin cells of the hypophysis, as well as on Leidig cells [13], is based on this effect [9].

Melatonin together with a change in the expression of its receptors in the suprachiasmatic core has a significant influence on regulation of neuron-pacemakers [19].

An increased level of prolactin, which is observed among patients with PADAM [8], leads to suppression of the impulse incretion of gonadotropin-releasing hormone and, consequentially, of the impulse rhythm of production of LH, FSH, and testosterone, as well as to suppression in impulse incretion of STH $[9,13]$.

Cortisol has an influence on the regulation of rhythms of the suprachiasmatic core, which is proven by the high concentration of receptors of corticosteroids in the suprachiasmatic core [20]. Any deviation in production of cortisol from the norm, whether it be a significant decrease in production (when patients have adrenalectomy) [21], or an increase in cortisol levels together with a reduced amplitude of its impulse incretion (when patients have PADAM), has a suppressive effect on neurons-pacemakers of the suprachiasmatic core [9].

Insulin resistance, which goes along with PADAM [8], leads to the exhaustion of $\beta$ cells and to a breakdown in the impulse incretion of insulin [13].

An age-related decrease in the production of testosterone leads to a loss of impulse rhythm and the establishment of a tonic incretion mode for luteinizing ( $\mathrm{LH}$ ), follicle-stimulating (FSH), and somatotropin (STH) hormones, as well as cortisol and insulin among men with PADAM, as well as to an increase in mitotic activity. These changes are accompanied by the development of metabolic syndrome (X-syndrome); their development can be inversed through androgen-replacement therapy. After the beginning of androgen-replacement therapy, patients with PADAM showed an increase in the amplitude of fluctuations of the levels of LH, FSH, STH, common testosterone, cortisol, and insulin (as compared to average values) [9].

\section{Mechanisms of Development of Insulin Resistance among Men With PADAM}

Insulin resistance, together with an increase in proliferate activity, are a partial manifestation of metabolic syndrome. The latter reflects the complex of compensatory-adaptive reactions which develop in aging men. This development is caused, to a great degree, by a decrease in testosterone production $[8,14,15,16]$. Insulin resistance is caused by a reduction in the expression of insulin receptors [13].

Standard genetically-determined variants of the functioning of the endocrine system have formed in the process of human evolution. Some of these variants come as compensatory reactions in the presence of pathological 
states of the human [16]. Resistance to insulin and leptin, which are accompanied by hyperphagia, an increase in glucose in the blood plasma, and an increase of fatty depots, is a widespread phenomenon in the animal world. The development of resistance to insulin and leptin in the summer months makes it possible to increase the mass of fatty tissue in animals for later use in the winter period [22]. This state develops temporarily under physiological conditions, and doesn't result in any negative consequences [16].

Leptin stimulates the production of neuropeptide $\mathrm{Y}$ through peptide synthesis in the hypothalamus. Neuropeptide $Y$ increases appetite, increases insulin and cortisol in the blood, and increases activity of the sympathetic nervous system [23].

The potential for development of resistance to insulin and leptin in people, inherited from people's distant animal ancestors, continues, but as a recessive trait. Under a number of pathological conditions, in particular among patients with PADAM, resistance to insulin and leptin is used for compensatory stimulation of division and differentiation of androgen-dependent cells (in particular for increasing production of insulin, which has mitogenic activity) $[8,14,15,16]$. This compensatory reaction is aimed at replacing the lack of endocrinal activators of division and differentiation [24,25], in particular insufficiency of testosterone $[8,14,15,16]$. Considering that the decrease in testosterone production progresses in men after 40 years of age, these people's resistance to insulin and leptin is constant, and leads to atherosclerosis, obesity and other complications $[8,9$, $14,15,16]$.

Reverse development of the given compensatory reactions is observed upon correction of partial age-related androgen deficiency. There is an increased expression of the insulin receptor gene when conducting androgen-replacement therapy among aging men [26], as well as a decrease in production of endogenous insulin (the surplus formation of which becomes unnecessary when regulation of insulin receptors is restored through testosterone therapy) [15]. The increase in the expression of insulin receptors received among patients with partial age-related androgen deficiency after the beginning of androgen-replacement therapy confirms the development of insulin resistance when reducing the production of sex hormones (as one of the main pathogenetic factors of type 2 diabetes) [16].

\section{The Influence of Partial Androgen Deficiency among Aging Men on Carbohydrate Metabolism}

Regulation as per the principle of negative feedback is common for many-stage enzymatic processes: when the level of the final product goes down, the intensity of the preceding reactions increases. "Activation by predecessors" is characteristic of these reactions: an increase in the levels of the preceding substrates stimulates formation of the product of the last stage. This behavior is common to all living organisms [27]. Cholesterol is the main predecessor of the formation of steroid hormones (including testosterone), and at earlier stages - glucose [27]. When testosterone production goes down with age, there is a compensatory increase in cholesterol and glucose levels - substrates for the subsequent synthesis of testosterone $[8,14,15,16]$. This conclusion was later proven by the ascertained increase in expression of several enzymes related to synthesis of cholesterol, combined with a decrease of testosterone production in men (after castration resulting from prostate cancer) [28].

The mechanism of insulin resistance which is formed in the process of phylogenesis is employed for a compensatory increase in the levels of the predecessors of testosterone - cholesterol and glucose - when there is an age-related reduction in testosterone production $[8,14,15,16]$. Insulin resistance upsets the transport and utilization of glucose. A blockade of insulin receptors of cells in the liver promotes an increase in the production of glucose (thanks to an increase in gluconeogenesis). Insulin resistance in skeletal muscles also induces an increase in the level of glucose in the blood, since the utilization of glucose in the muscles is one of the main mechanisms of its metabolism. As a response to a disruption of the transport and metabolism of glucose, and 
an increase in the level of insulin, neurons of the hypothalamus increte growth hormone-releasing factor and corticotrophin-releasing hormone into the portal system of the hypophysis, leading to an increase in the levels of anti-insular hormones, like STH and cortisol [13,29].

The level of glucagon in the presence of insulin-dependent sugar diabetes increases constantly, and doesn't go down after a patient eats [30].

IGF-1- connecting proteins restrain the interaction of IGF-1 and insulin with receptors, thereby inhibiting their influence on cell-targets [13]. A reduction in the level of IGF-1- connecting proteins intensifies the influence of IGF-1 and insulin [25,31]. Insulin suppresses synthesis of IGF-1 - connecting proteins [25,32]. Insulin receptors are also additionally activated by IGF-1. An increase in the level of estrogens in the presence of PADAM further increases the incretion of STH, which in turn stimulates the formation of IGF-1 $[8,13]$.

Thus, hyperinsulinism helps overcome insulin resistance $[8,14,15,16]$. An increase in the levels of insulin, STH, and IGF-1, and, consequently, of their mitotic activity among patients with PADAM, is a compensatory reaction to the development of insulin resistance [8].

Insulin, which is an activator of enzymes of glycolysis, and a suppressor of the enzymes of gluconeogenesis, controls the correlation of activity of these processes [27]. Glucocorticoids serve as an activator of the enzymes of gluconeogenesis and as a suppressor of the enzymes of glycogenesis [30]. Therefore, in the presence of insulin resistance, which is accompanied by an increase in the incretion of corticosteroids and a decrease in the influence of insulin, the intensity of gluconeogenesis by means of the stimulation of the corresponding enzymes in the liver and the kidneys increases [27]. Insulin resistance, and the increase in insulin which accompanies it, leads to dislipoproteinemia, especially to hypertriglyceridemia, since the surplus of insulin stimulates lipogenesis and the synthesis of low-density lipoprotein in the liver [13].

Among patients with insulin-dependent sugar diabetes (2nd-type diabetes) and obesity, the level of glucose in the blood plasma can remain within normal ranges before the stage of decompensation of $\beta$-cells, despite the activation of gluconeogenesis and the infringement of the utilization of glucose (or exceed the normal levels in insignificant amounts). At the same time, the level of insulin in such patients increases by 1.5-3 times [33]. This leads to exhaustion of $\beta$-cells of the pancreas [13].

Insulin sensitivity of adipocytes is inversely proportional to the sizes of the cell. Hyperinsulinemia, which precedes obesity, leads to growth of the content of lipids in the cell, as well as to an increase in the sizes of adipocytes. The larger the adipocyte, the less sensitive it is to insulin, which testifies to the fact that the capacity of fatty depots is reduced. Fat depots are depots of the second type after glycogen of the liver for the utilization of glucose, the surplus quantity of which remains in them, transforming itself into fatty acids and glycerin, and then into triglycerides. An increase in the correlation of the circumference of the waist to the circumference of the hips testifies to the presence of insulin resistance. Compensatorily, STH intensifies cell proliferation, which, among other things, helps increase the amount of cells of fatty tissue [13,25,34]. Thus, the replication of preadipocytes, with the resulting transformation of the preadipocytes into real fatty cells, as well as hyperinsulinemia, which leads to an additional quantity of lipids entering fatty cells, increases the capacity of fat depots and promotes the development of obesity $[8,14,15,16]$.

An intensification of aromatase activity in the presence of PADAM and an increase of the aromatization of testosterone and androstenedione $[8,11,15,35]$ is combined with a significant increase in body mass among men. An increase in the level of estrogens in the blood and the intensification of their intake by the tissues of the organism can be observed among men suffering from obesity [36,37]. An increase in the level of estrogens formed stimulates an increase in the quantity and sizes of the adipocytes, as well as in the quantity of stromal cells of fatty tissue $[37,38]$. Stromal cells of fatty tissue are themselves capable of synthesizing both estrogens 
and androgens [39]. Their incretion, in turn, has a stimulating effect on the development of fatty tissue, and a vicious circle is formed. Lymphocytes and macrophages, which also have aromatase activity, add to the given effect [37].

An increased level of glucocorticoids, IGF-1 and a series of other peptides which activate estrogen receptors, supplement the effect of estradiol, which is connected with an increase of the number and sizes of adipocytes, and of the quantity of stromal cells in the fatty tissue. This effect is the result of homology of individual parts of their receptors to estrogen receptors [25,40]. An increase in the level of regulating factor is accompanied by the activation of the according receptors [29]. The increase in glucocorticoid and estradiol production is accompanied by an increase in the expression of homologous corticosteroid and estrogen receptors $[25,40]$. An increase in the number and size of adipocytes exponentiates the effect of the aromatase held in them $[8,14$, $15,16]$.

Thus, the development of insulin resistance among men with PADAM, which is accompanied by an increase in the levels of glucose, cholesterol, triglycerides, insulin, STH, IGF-1, adrenocorticotropic hormone, and cortisol, as well as by an increased share of fatty tissue, is caused, to a significant degree, by testicular insufficiency. An inverse development of the above-mentioned pathological processes is impossible without correction of age-related androgen deficiency $[8,14,15,16]$.

\section{The Influence of Partial Androgen Deficiency among Aging Men on the Imimune SYSTEM AND MICROCIRCULATION}

Reactions of natural immunity are initiated by chemical structures including end sugars of the membrane glycoproteins that contain mannose. Protection of the membrane glycoproteins by sialic acids breaks down among old, proliferative, malignant cells. Free mannose appears on the surface of these cells. The given cells become accessible to identification [41]. The above-mentioned changes among patients with PADAM are stipulated by an increase in the level of a series of mytogenic factors: STH, insulin, basic fibroblast growth factor (bFGF) and others $[8,14,15]$.

Tumor necrosis factor- $\alpha(\mathrm{TNF} \alpha)$, hydrolases (acid phosphatase, alkaline phosphatases, serine proteinases and esterases), components of the compliment, and highly-active forms of oxygen and nitrogen are all responsible for influencing the cytolytic (including anti-tumor) activity of monocytes, macrophages, neutrophils, and cytotoxic T-cells. TNF $\alpha$ contains an expressed cytotoxicity, which is shown in the destruction of tumorous cells. In addition to cytotoxic activity, TNF $\alpha$ also connects with specific highly-active membrane receptors, especially with TNF-R1, which gives a domain for cell death, thereby helping the program of apoptosis to be started [41,42]. Acid phosphatase, which has cytotoxic activity, is found in macrophages, in primary (auzorophile) granules of neutrophils, and in several other cells of the immune system $[41,42]$. Alkaline phosphatase also has cytotoxic activity. Alkaline phosphatase is found in secondary (specific) granules of neutrophils and, together with other highly-active substances and enzymes, is capable of provoking the death of tumorous cells [41].

Granules of macrophages, neutrophils, and cytotoxic T-cells also contain serine proteinases and esterases of a chemotripsin type. Regulation of the activity of proteinases is done by their inhibitors, which are increted by macrophages: $\alpha$-antichemotripsin and $\alpha 2$-macroglobulin. Serine proteinases participate in the antibody-independent alternative way of activating the complement. Besides the expression of cytotoxicity, serine proteinases can also stimulate the launch of a program of apoptosis in cell-targets, influencing the paths of inner-cell signaling [41,42].

The formation of free radicals, peroxides, and other highly active products is accompanied by a high rate of glucose consumption. The oxidation of glucose through the pentose-phosphate path is accompanied by an accumulation of NADPH; the interaction of the latter with oxygen molecules leads to the formation of 
superoxide-anion $\left(\mathrm{O}_{2}^{-}\right)$. In following reactions, hydrogen peroxide is formed $\left(\mathrm{H}_{2} \mathrm{O}_{2}\right)$, as well as hydroxyl-radical $\left(\mathrm{OH}^{-}\right)$and other products that provoke cell death $[41,42]$.

$\mathrm{Ca}^{++}$takes part in the activation of the compliment, in the perphorin-dependent mechanism of interaction with the target cytotoxic T-cells [41,42].

Increased values of TNF $\alpha$, acid phosphatase and alkaline phosphatase, as well as of the value of peroxidation of lipids and calcium when testosterone production goes down, testifies to the development of a compensatory reaction of anti-tumor cell immunity in response to an increase in proliferative activity among patients with PADAM. This reaction is aimed at removal of the atypical cells that form and at regulating apoptosis $[8,14,15]$.

Peroxidation of low-density and very low-density lipoproteins by products of the active form of oxygen and nitrogen, increted by neutrophils, leads to formation of their peroxide-modified forms that have high atherogenicity. Activation of macrophages makes it possible for macrophages to take over the products formed. High concentrations of esterified and free cholesterol are collected in the cytoplasm of arterial macrophages, thereby transforming them into foamy cells. When these cells are destroyed, cholesterol is then collected in the walls of the arteries [27]. An increased level of glucose, which is necessary for this process, is supported thanks to insulin resistance. When the level of testosterone goes down, insulin resistance goes up regularly, which points to an intensification of the given compensatory mechanism $[8,14,15]$.

Participation of the proteolytic enzymes of neutrophils in the development of the vascular component of the inflammatory reaction makes for a change in the contractibility and permeability of small vessels. For example, serine proteinase, which is made by neutrophils, leads to the formation of angiotensin II from angiotensinogen of the plasma. Specific granules of neutrophils increte enzymes that are similar to proteases of the system of the compliment, and which are capable of chipping off vasoactive peptide C5a from the C5 molecule. An increase in the formation of the activator of plasminogen, platelet activating factor, $\mathrm{TNF} \alpha$, products of the respiratory burst and overoxidation, changes in properties of the endothelium, and reductibility and permeability of small blood vessels have an effect on thrombocytic hemostasis, thereby increasing the risk of thrombosis [43].

PADAM, which initiates a response to natural immunity, leads to the development of such diseases and pathological states as atherosclerosis, hypertension, violation of microcirculation and an increase in the risk of thrombosis. It also promotes development of cardiovascular and brain irregularities, and pathology of the connective tissue (with a decrease in the tissue's strength). An increase in the levels of TNF $\alpha$, products of the active form of oxygen and nitrogen and overoxidation lead to a breakdown in the structure of the connective tissue, and have a negative influence on the restoration of its components among older men with PADAM. This promotes the development of such diseases as hernias at various locations, aneurisms of blood vessels, and several others $[8,14,15,16]$.

The hormones and receptors corresponding to them of mucous cells and tissues form a united inter-dependent system [29]. An increase in the expression of androgen receptors compensates for the inadequate production of androgens in men of older age groups and accompanies atrophy of androgen-dependent tissues. After the beginning of performing androgen-replacement therapy, the expression of androgen receptors consistently decreases [16].

The phenomena of parakeratosis and atrophic changes, which include a decrease in the thickness of the epithelial layer (due to less expressed development of basal and parabasal layers), a lower number of small blood vessels, as well as signs of dystrophic changes of epithelial cells (the presence of cells with optically empty cytoplasm), increased indicators of the intensity of cell proliferation (Ki67) and inhibition of apoptosis (bcl-2) is observed among patients with partial age-related androgen deficiency [16]. 
Correction in the testosterone level among patients with PADAM, which leads to a decrease in the levels of mytogenic factors (STH, insulin, main fibroblast growth factor), leads to the reverse development of compensatory reactions to natural cell immunity: a decrease in the level of TNF $\alpha$ and a decrease in the value of highly-active forms of oxygen and nitrogen (revealed by a decrease in the levels of peroxidation of lipids products) [15]. When conducting androgen-replacement therapy there is inverse development of the given pathological processes. An improvement in microcirculation is testified to by the consistent increase in the constant composition of perfusion, as well as by an increase in the number of small vessels and blood filling of androgen-dependent tissues, noted during histological study [16].

\section{PADAM AND ARTERIAL HYPERTENSION}

A decrease in testosterone production leads to an increase in the levels of luteinizing, follicle-stimulating, parathyroid and adrenocorticotropic hormones, as well as to a decrease in the amplitude of their impulse incretion $[8,9,11,15]$. Besides genital glands (for luteinizing and follicle-stimulating hormones), the cortex of the adrenal glands (for adrenocorticotropic hormone), and bone tissue and kidneys (for parathyroid hormone), receptors for these hormones are found in many other tissues [13].

Breakdowns in the process of division and differentiation of androgen-dependent cells under a decrease in testosterone production among aging men are accompanied by a compensatory increase in production of cell growth factors: insulin-like growth factor-1 (IGF-1), epidermal growth factor (EGF), basic growth factor of fibroblasts (bFGF), and others under the autocrinal-paracrinal mechanism [8,9,10,14,15,26].

A reduction in the pool of stem cells among people over 35-40 years old also leads to atrophy and to an additional increase in production of cell growth factors. An increase in cell growth factors is aimed at stimulating division (and, accordingly, an increase in the number) of cambial cells-predecessors [2,4].

Changes in hormonal regulation among patients over 35-40 years old with PADAM are reflected on the path of the transmission of the signal [16]. cAMP is an intracellular mediator. Initiation of the cAMP-path of signal transmission develops after binding together of the receptor of the cell surface with the according ligand [7]. A number of peptide hormones (luteinizing hormone, follicle-stimulating hormone, parathyroid hormone, adrenocorticotropic hormone, and several others) can serve as a ligand [13]. Thus, an increase in the production of these peptide hormones under partial age-related androgen deficiency $[8,14,15]$, leading to activation of cAMP-paths of signal transmission, besides other effects, influences the regulation of the tone of smooth muscle fiber [16].

In order to understand pathogenetic mechanisms for increasing tone of smooth muscle fiber together with cAMP-paths of signal transmission, it's necessary to keep in mind the inositol phospholipid path (Ca-messenger system) from surface cell receptors. The mitotic effect of the majority of cell growth factors takes place through the inositol phospholipid path of signal transmission [7], as well as through the cAMP-paths of signal transmission (including activity of tyrosine-kinase) [16]. The effect of a series of cell growth factors (when involving the Ca-messenger system) is mediated by the formation of diacilglicerol. Diacilglicerol activates protein kinase $\mathrm{C}$, which is accompanied by stimulation of proliferation of cells. Liberation of $\mathrm{Ca}^{++}$from cell repositories promotes the given process, leading to increased tone of smooth muscle cells. Diacilglicerol then breaks down to arachidonic acid, which is necessary for synthesis of prostaglandin. Initiation of the synthesis of prostaglandin leads to an additional increased tone of smooth muscle cells [7]. This mechanism, apparently, not only promotes a violation of microcirculation, but also development of hypertension, dysuria (as a result of the increase in tone of smooth muscles of the urinary bladder and the prostate gland), chronic obstructive disease of the lungs and other pathological states among aging men as a result of increased smooth muscle tone $[11,16]$. Apparently, interaction between all paths of signal transmission is significant [16]. 
Affecting the path of signal transmission shouldn't be viewed as the only way to solving the problem of increased tone of smooth musculature among people of older age groups. The studied mechanisms of signal transmission are universal: they are used in all cells of animals and man. Therefore, pharmacological medications which have an influence on the signal transmission path don't have a selective medical effect. The use of such medications (especially over a long period of time) is limited by a series of side effects [16].

Normalization of the tone of smooth muscle fibers can help to rehabilitate hormonal regulation of androgen-dependent tissues (by providing adequate androgen-replacement therapy), and also, in the future, by restoring the pool of pluripotent stem cells which replenish the number of progenitor cells of the epithelium and other tissues [2,3,4]. Androgen-replacement therapy in patients with PADAM is effective for reducing manifestations of metabolic syndrome, including hypertension [16].

\section{The Influence of Age-Specific Decreases in Testosterone Production on Mineral METABOLISM}

The mass of bony tissue among all people is slowly reduced after 30 years of age. The speed of the loss of bone mass is higher among women than among men [13]. An increase in the risk of osteoporosis among men with primary hypogonadism and among women with a deficit of estrogens in the period of menopause results from a rise in the threshold of sensitivity of the cells of the parathyroid glands to calcium, as a result of which the mechanism of suppression of the incretion of parathyroid hormone in answer to hypercalcemia is broken. As a result, the cells of the parathyroid glands increte a surplus amount of PTH. Accordingly, the level of the incretion of calcitonin is reduced $[8,13,15]$.

A surplus incretion of PTH increases the calcium loss from the bones, which leads to hypercalcemia. The resorption of phosphates in the kidneys is reduced under the influence of a surplus of PTH, and phosphaturia and hypophosphatemia arise. The tubular absorption of calcium is increased, but this effect of PTH is balanced out by an increased glomerular filtration of calcium as a result of hypercalcemia; thus calcium in the urine increases [13]. PTH receptors are present on the osteoblasts and osteocytes, but are not present on osteoclasts. Nevertheless, when the level of PTH increases, osteoclasts are activated, and the resorption of bone tissue is accelerated. This effect of PTH is mediated by osteoblasts: under the influence of PTH osteoblasts begin to increte IGF-1 and cytokines, which in their turn activate osteoclasts. This is assisted by the enhanced proliferation of cells-predecessors of osteoclasts, which have PTH receptors [13]. When the level of PTH is constantly high, the resorption of bone tissue predominates over its formation, which leads to osteopenin. Stimulation of IGF-1 when PTH incretion increases [13] has the effect of additionally increasing the level of IGF-1 among patients with PADAM [8].

Insulin resistance accompanies an age-related decrease in testosterone production [8,15,16]. A disruption of the hormonal action of insulin in the presence of insulin resistance is accompanied by a decrease in the activity of osteoblasts, which promotes osteoporosis and hypercalcemia [13].

The incretion of corticotropin-releasing hormone into the portal system of the hypophysis during a blockade of insulin receptors promotes an incretion of adrenocorticotropic hormone, which strengthens the incretion of cortisol in the cortex of the adrenal glands. Cortisol suppresses the activity of the osteoblasts [13].

A surplus of PTH and hypophosphatemia stimulate synthesis of $1.25(\mathrm{OH})_{2} \mathrm{D}_{3}$ in the renal tubules. The levels of calcitonin, estrogens and insulin also influence the formation of $1.25(\mathrm{OH})_{2} \mathrm{D}_{3}$. Under the influence of $1.25(\mathrm{OH})_{2} \mathrm{D}_{3}$ the absorption of calcium in the intestines is increased, which strengthens hypercalcemia even more [13]. When the level of testosterone is decreased, the level of $25-\mathrm{OHVitD}_{3}$ is increased [8].

Calcitonin slows down the resorption of bone tissue by reducing the activity of osteoclasts and by stimulating osteoblasts. When the level of sex hormones is decreased, in women with a deficit of estrogens, as conditioned 
by menopause, and in men with a deficit of androgens due to PADAM, the incretion of calcitonin is decreased, which promotes faster resorption of bone tissue $[13,14]$.

Surplus formation of thyroid hormones, as conditioned by the increase in the level of $17 \beta$-estradiol, stimulates osteoclasts, which additionally leads to an intensification of the resorption of bone tissue [13].

When PTH incretion increases, one can observe an increase in the activity of alkaline phosphatase. Alkaline phosphatase is produced in the bones by osteoblasts and the content of alkaline phosphatase increases during periods of increased osteoblast activity. The activity of osteoblasts and that of osteoclasts are closely linked between themselves, thus any intensification in the metabolic processes in the bones leads to an increase in the concentration of alkaline phosphatase [13,29].

Older people are sensitive to even light hypercalcemia. The peak of hypercalcemia comes at 60-70 years of age. Damage of the central nervous system, of the cardiovascular system, of the kidneys, and of the stomach-intestine tract is strongest in the medical picture. The strength of the bone tissue remains comparatively stable until the 50-year age bracket, after which the strength of the bones of representatives of both sexes begins to decrease. Among women this process becomes much faster during menopause. Among men, a steep drop in the curve of the reduction of the bone mass isn't observed, since, unlike women, in the period of andropause there is not a sudden decrease in the content of sex hormones among men. A prescription of estrogen preparations prevents hypercalcemia and a further loss of bone mass among women $[13,29]$. Among men, a prescription of androgen-replacement therapy seems to be a promising way to prevent osteoporosis [15].

PTH receptors are found not only in bone tissue and the kidneys, but in many other tissues and organs in which PTH takes part in the metabolism of calcium and phosphorus [13]. Apparently, an increase in the threshold of sensitivity to calcium during menopause among women, and during PADAM among men, is distributed not only to parathyroid glands, but to the remaining tissues which contain PTH receptors. An illusion of hypocalcemia is created, which compensatorily promotes intensive synthesis of PTH by the parathyroid glands, as well as outside-thyroid production of the analogue of PTH - PTH-like peptides made by the periphery tissues.

The stimulation of the synthesis of PTH promotes hyperplasia (and, more rarely, of adenoma) of the parathyroid glands $[13,14]$.

\section{Perspective Methods of Prevention and Treatment of Padam and Metabolic SYNDROME}

Androgen-dependent cells require the presence of a physiologically necessary level of testosterone for further development. When there is an obvious need to conduct androgen-replacement therapy for men over 35-40 years old, the daily dose of testosterone which enters the blood plasma should correspond to the quantity of the testosterone that decreases with age. Prescribing a large dose of the preparation leads to suppression of the body's own testosterone production, while losing the circadian rhythm of incretion [17]. When calculating the daily dose of testosterone, one should take into account the average daily production of testosterone in men [17]: $7 \mathrm{mg} /$ day [44]. One should also take the age-related decrease in testosterone production of $1 \%$ per year on average after $35-40$ years of age for common testosterone into account [2,17]. Androgen replacement therapy should be conducted continually [17].

A perspective method for restoration of one's own production testosterone and decreasing excess stimulation of mitotic activity in people 40 years of age and older is the restoration of the number of a pool of pluripotent stem cells by transfusion of mononuclear fraction of peripheral blood from young donors 18-23 years of age with the same blood types and sex as the recipient $[2,3,4]$. 


\section{CONCLUSION}

Insulin resistance, together with an increase in proliferate activity, is a partial manifestation of metabolic syndrome (X-syndrome), the development of which among men is due, to a significant extent, to a decrease in the production of testosterone and violation of tissue renewal. The recovery of testosterone production and regeneration helps to reduce insulin resistance, atherogenic dislipoproteinemia, obesity, hypertension, osteoporosis, as well as decrease proliferative activity, and rehabilitate the regulation of division and differentiation of androgen-dependent cells of various tissues and organs among older men $[3,4,8,15,45,46$, $47,48,49]$.

\section{REFERENCES}

1. Teplyashin AS, Korzhikova SV, Sharifullina SZ, Chupikova NI, Rostovskaya MS, Savchenkova IP. Characteristics of human mesenchymal stem cells isolated from bone marrow and adipose tissue. Tsitologiya. 2005; 47(2): 130-5.

2. Pechersky AV, Pechersky VI, Aseev MV, Droblenkov AV, Semiglazov VF. Several aspects of the regeneration process carried out by means of pluripotent stem cells. Tsitologiya. 2008; 50(6): 511-20.

3. Pechersky AV, Pechersky VI, Smolyaninov AB, Vilyaninov VN, Adylov SF, Semiglazov VF. Implementing cellular technologies to restore regeneration process in people of older age groups. Bulletin of the North-Western State Medical University named after II Mechnikov. 2014; 6(4): 52-62.

4. Pechersky AV, Pechersky VI, Smolyaninov AB, Velyaninov VN, Adylov SF, Shmelev AYu, Pecherskaya OV, Semiglazov VF. Regeneration and carcinogenesis. Journal of Stem Cells. 2015; 10(4): 255-70.

5. Gray A, Feldman HA, McKinlay JB, Longcope C. Age, disease, and changing sex-hormone levels in middle-aged men: Results of the Massachusetts male aging study. J Clin. Endocinol. 1991; 73(2): 1016-25.

6. Lopatkin NA, editor. Guide to Urology. Moscow: Medicine; 1998.

7. Alberts B, Bray D, Lewis J, Raff M, Roberts K, Watson JD. Molecular biology of the cell. Moscow: Mir; 1994.

8. Pechersky AV, Semiglazov VF, Loran OB, Mazurov VI, Karpishchenko VF, Nikiforov VF, Kalinina NM, Drygina LB, Davydova NI, Skorobogatykh MG. Changes in cytokine levels in patients with prostate cancer after orchiectomy. TERRA MEDICA nova, special edition "Laboratory diagnostics". 2003; 2: 26-30.

9. Pechersky AV, Semiglazov VF, Loran OB, Karpishenko AI, Pechersky VI, Mazurov VI. The influence of partial androgen deficiency (PADAM) on the impulse regime of incretion of several hormones and mitotic activity. Tsitologiya. 2006; 48(10): 862-6.

10. Pechersky AV, Semiglazov VF, Komyakov BK, Guliyev BG, Gorelov AI, Novikov AI, Pechersky VI, Simonov NN, Gulyayev AV, Samusenko IA, Vonsky MS, Mittenberg AG, Loran OB. Changes in the expression of steroid hormone receptors during development of partial androgen deficiency (PADAM). Tsitologiya. 2005; 47(4): 311-7.

11. Pechersky AV, Semiglazov VF, Mazurov VI, Karpischenko AI, Mikhailichenko VV, Udintsev AV. Androgen administration in middle-aged and ageing men: effects of oral testosterone undecanoate on dihydrotestosterone, estradiol and prostate volume. International Journal of Andrology. 2002; 25: 119-25.

12. Vermeulen A, Kaufman JM. Androgens and cardiovascular disease in men and women. Aging Male. 1998; (1): 35-50.

13. Lavin N, editor. Endocrinology. 2nd ed. Moscow: Practica Press; 1999.

14. Pechersky AV. Partial androgen deficiency among aging men. Influence on the growth of metabolic syndrome and pathology of the prostate gland, 3rd ed. St. Petersburg: SPb MAPO; 2007.

15. Pechersky AV, Semiglazov VF, Mazurov VI, Karpishchenko AI, Pechersky VI, Zybina NN, Davydova NI, Kravtsov VYu, Proshin SN, Skorobogatykh MG, Loran OB. The influence of partial androgen deficiency of aging men on the development of metabolic syndrome. TERRA MEDICA nova, special edition "Laboratory diagnostics". 2006; 4: 12-9. 
16. Pechersky AV, Dombrovskaya YA, Pecherskaya OV, Moroz BT. The role of sex hormones in regulating the expression of insulin receptors and microcirculation. Bulletin of St-Petersburg Medical Academy of Postgraduate Studies. 2010; 2(1): 28-33.

17. Pechersky A. Features of diagnostics and treatment of partial androgen deficiency of aging men. Central European Journal of Urology. 2014; 67(4): 397-404.

18. Montanari E, Guarneri A, DellOrto P, Gelosa M. Etiopathogenesis of benign prostatic hyperptrophy. Arch Ital Urol Androl. 1995; 67(1): 7-12.

19. Klein DC, Moore RY, Reppert SM. Suprachiasmatic nucleus: The mind's clock. New York: Oxford Univ; 1991.

20. De Kloet ER, Rosenfeld P, Van Eekelen JAM, Sutanto W, Levine S. Stress, glucocorticoids and development. Progress in Brain Research. 1988; 73: 101-20.

21. Arduinin D, Rizzo G, Parlad E, Dell'Acqua S, Romanini C, Mancuso S. Los of circadian rhythms of fetal behavior in a totally adrenalectomized pregnant woman. Gynecological Obstetrical Investigations. 1987; 23: 226-9.

22. Florant GL, Porst H, Peiffer A, Hudachek SF, Pittman C, Summers SA, Rajala MW, Scherer PE. Fat-cell mass, serum leptin and adiponectin changes during weight gain and loss in yellow-bellied marmots (Marmota flaviventris). Journal of Comparative Physiology. 2004; 174 (8): 633-9.

23. Stephens TW, Basinski M, Bristow PK, Bue-Valleskey JM, Burgett SG, Craft L, Hale J, Hoffmann J, Hsiung HM, Kriauciunas A, Mackellar W, Rosteck JR PR, Schoner B, Smith D, Tinsley FC, Zhang X-Y, Heiman M. The role of neuropeptide $Y$ in the antiobesity action of the obese gene product. Nature. 1995; 377: 530-2.

24. Vasilyev YuM. Social behavior of normal cells and anti-social behavior of timorous cells. Soros Educational Journal. 1997; 4: 17-22.

25. Bershtein LM. Hormonal carcinogenesis. St. Petersburg: Nauka; 2000.

26. Pechersky AV, Loran OB, Pechersky VI, Vonsky MS, Mittenberg AG, Semiglazov VF. The role of testosterone in regulation of the expression of genes of several proliferation factors. Tsitologiya. 2006; 48(10): 856-61.

27. Berezov TT, Korovkin BF. Biological Chemistry. Moscow: Medicina; 2004.

28. Leon CG, Locke JA, Adomat HH, Etinger SL, Twiddy AL, Neumann RD, Nelson CC, Guns ES, Wasan KM. Alterations in cholesterol regulation contribute to the production of intratumoral androgens during progression to castration-resistant prostate cancer in a mouse xenograft model. Prostate. 2009; 70(4): 390-400.

29. Kettail VM, Arki PA. Pathophysiology of the endocrinal system. Saint-Petersburg: Nevsky Dialect; 2001.

30. Karpishenko AI. Medicinal Laboratory Diagnostics. Saint-Petersburg: Intermedika; 2001.

31. Cohen P, Peehl DM, Graves HCR, Rosenfeld RG. Biological effects of prostate specific antigen as an insulin-like growth factor binding protein-3 protease. Endocrinol. 1994; 142: 407-15.

32. Rutanen EM, Nyman T, Lehtovirta P, Ammala M, Pekonen F. Suppressed expression of insulin-like growth factor binding protein-1 mRNA in the endometrium: a molecular mechanism associating endometrial cancer its risk factors. Int J Cancer. 1994; 59: 307-12.

33. Ginzburg MM, Kryukov NN. Obesity. Moscow: Medpractika; 2002.

34. Kliorin AI. Obesity in children. Leningrad: Medicine; 1989.

35. Pechersky AV, Mazurov VI, Semiglazov VF, Karpischenko AI, Udintsev AV. The influence of the level of testosterone on the formation of $5 \alpha$-dihydrotestosterone and $17 \beta$-estradiol in the testosterone-sensitive cell line of fibroblasts of the foreskin. Tsitologiya. 2005; 47(2): 172-4.

36. Schneider J, Kirschner MA, Berkowitz R, Ertel NH. Increased estrogen production in obese men. Clin Endocrinol and Metabol. 1979; 48: 633-8.

37. Bershtein LM. Extragonadal production of estrogens (their role in physiology and pathology). Saint-Petersburg: Nauka; 1998.

38. Hirsch J, Leibel RL. A biological basis of human obesity. Clin Endocrinol and Metabol. 1991; 73: 1153-7. 
Role of Partial Androgen Deficiency of Aging Men in Development of the Metabolic Syndrome

39. Perel E, Daniilescu D, Kindler S, Killinger DV, Kharlip L. The formation of 5-alpha-reduced androgens in stromal cells from human breast adipose tissue. Clin Endocrinol and Metabol. 1986; 62: 314-8.

40. Tsai MJ, Clark J, Schrader WT, O'Malley BW. Mechanisms of action of hormones that act as transcription-regulatory factors. Wilson JD, editor. Williams text-book of endocrinology (Philadelphia): W B Saunders; 1998.

41. Yarilin AA. Fundamentals of Immunology. Moscow: Medicina; 1999.

42. Roitt I, Brostoff J, Male D. Immunology. Moscow: Mir; 2000.

43. Alekseeva LA, Ragimov AA, Nikiforov YuV. DIC syndrome. Ragimov AA, Eryomenko AA, Nikiforov YuV, editors. Transfusiology in resuscitation (Moscow): Medical Information Agency; 2005.

44. Morales A, Schulman C, Tostain J, Wu F. Selecting the correct terminology for testosterone deficiency. Clin Endocrinol Metab. 2006; 50: 407-9.

45. Pechersky AV. Revisiting terminology and characteristics of stem cells. Journal of Stem Cells. 2016; 11(2): 63-7.

46. Pechersky AV, Pechersky VI, Aseev MV, Droblenkov AV, Semiglazov VF. Immune system and regeneration. Journal of Stem Cells. 2016; 11(2): 69-87.

47. Pechersky AV, Pechersky VI, Shpilenya ES, Gaziev AH, Semiglazov VF. Regeneration and cicatrization. Journal of Stem Cells. 2016; 11(2): 89-97.

48. Pechersky AV. Influence of violation of regeneration in people over 35-40 years old on decrease in production of sexual hormones. Journal of Stem Cells, 2016; 11(2): 99-109.

49. Pechersky AV. The role of partial androgen deficiency in aging men in the development of benign prostatic hyperplasia and prostate cancer. Molecular Inhibitors in Targeted Therapy. 2016; 2(1): 1-13.

Citation: Alexander V. Pechersky. "Role of Partial Androgen Deficiency of Aging Men in Development of the Metabolic Syndrome". American Research Journal of Urology; 1(1): 10-22.

Copyright (C) Alexander V. Pechersky, This is an open access article distributed under the Creative Commons Attribution License, which permits unrestricted use, distribution, and reproduction in any medium, provided the original work is properly cited. 